\title{
O DIREITO À CIDADE: ENTRE A SEGREGAÇÃO SOCIOESPACIAL E A BUSCA POR CIDADES SUSTENTÁVEIS
}

\section{CITY LAW: IN BETWEEN SOCIO-SPATIAL SEGREGATION AND THE SEARCH FOR SUSTAINABLE CITIES}

\author{
Luiz Claudio Gonçalves Junior ${ }^{1}$ \\ Zenildo Bodnar ${ }^{2}$ \\ Patrícia Bianchi ${ }^{3}$
}

\section{RESUMO}

No artigo analisa-se o direito à cidade sustentável sob o enfoque da complexidade, num contexto de segregação socioespacial. Em seguida, estabelece-se uma ligação entre a construção e desenvolvimento da cidade com a chamada injustiça socioambiental. Destaca-se, no estudo, a importância da realização de políticas públicas de desenvolvimento urbano com a participação da sociedade civil, com o propósito de se aperfeiçoar o bem-estar urbano da coletividade e de se construir, de fato, uma cidade sustentável. Conclui-se que, nesse processo, o Estado deverá melhor estruturar o seu poder regulador com relação ao capital das cidades, a fim de que este capital não se perpetue em benefício de uma elite, evitando-se, dessa forma, aumentar o desequilíbrio e as desigualdades nos centros urbanos. Por fim, a cidade deve iniciar um processo de transformação, mediante a construção de um programa político de reforma urbana direcionado ao atendimento às necessidades coletivas. No trabalho, utilizou-se o método de abordagem indutivo, método de procedimento monográfico e técnica de pesquisa bibliográfica.

\footnotetext{
${ }^{1}$ Bacharel em Direito pelo Centro Universitário Salesiano de São Paulo/U.E. Lorena - UNISAL. Pós-graduado em Direito do Estado e mestre em Biodireito, Ética e Cidadania pelo Centro Universitário Salesiano de São Paulo/U.E. Lorena - UNISAL. Doutor em Educação pela Universidade Metodista de Piracicaba - UNIMEP. Licenciando em História pela Universidade Federal do Estado do Rio de Janeiro - UNIRIO. Professor e pesquisador do Centro Universitário de Volta Redonda / Fundação Oswaldo Aranha - UniFOA. Lattes: http://lattes.cnpq.br/1171027902173018 ORCID: https://orcid.org/0000-0002-6917-3394 E-mail: Iclaudiojr@uol.com.br

2 Possui graduação em Direito pela Universidade Estadual de Ponta Grossa, Mestrado em Ciência Jurídica pela Universidade do Vale do Itajaí, Mestrado em Urbanismo, História e Arquitetura da Cidade, Doutorado em Direito pela Universidade Federal de Santa Catarina, Doutorado em Ciências Humanas pela Universidade Federal de Santa Catarina, Pós Doutorado em Direito Ambiental na Universidade Federal de Santa Catarina e Pós Doutorado em Direito Ambiental pela Universidade de Alicante - Espanha. Professor nos programas de Doutorado e Mestrado em Ciência Jurídica da Universidade do Vale do Itajaí. Foi Juiz Federal e atualmente é Registrador de Imóveis. Lattes: http://lattes.cnpq.br/9173159162465306 ORCID: https://orcid.org/0000-0002-1168-3260 E-mail: zenildo@univali.br

${ }^{3}$ Pós-doutora em Direito na Universidade de São Paulo - USP. Doutora em Direito pela Universidade Federal de Santa Catarina - UFSC, Professora na Graduação e no Programa de Mestrado em Direito do Centro Universitário Salesiano de São Paulo - UNISAL. Lattes: http://lattes.cnpq.br/0619465556128400 ORCID: https://orcid.org/0000-0002-78793157 E-mail: patricianbianchi@gmail.com
} 
Palavras-chave: 1. Cidade Sustentável; 2. Direito à Cidade; 3. Meio Ambiente Urbano; 4. Políticas Públicas; 5. Segregação Socioespacial.

\section{ABSTRACT}

The article analyzes the right to a sustainable city from the point of view of complexity, in a context of socio-spatial segregation. Then, a connection is established between the construction and development of the city and the so-called socio-environmental injustice. The study highlights the importance of public policies for urban development with the participation of civil society in order to improve the urban wellbeing of the community and to build a sustainable city. We conclude that in this process the State should better structure its regulatory power with regard to the capital of the cities so that this capital is not perpetuated for the benefit of an elite, thus avoiding increasing the imbalance and inequalities in urban centers. Finally, the city must begin a process of transformation by building a political program of urban reform aimed at meeting collective needs. In the article, the inductive approach method, monographic procedure method, and bibliographic research technique were used.

Keywords: 1. Sustainable City; 2. City Law; 3. Urban Environment; 4. Public Policies; 5. Socio-spatial segregation.

\section{INTRODUÇÃO}

O homem sempre viveu em comunidades, aldeias isoladas ou tribos Como um animal tipicamente social, moldou e fixou-se nos locais que the trouxeram melhores condições de sobrevivência. Aprendeu a explorar os recursos naturais e transformou o seu habitat e o seu comportamento, a fim de se adaptar aos novos processos histórico-expansionistas. As Revoluções Industriais e Comerciais geraram a expansão de processos econômicos, políticos, culturais e sociais, bem como avanços tecnológicos, fomentando o dinamismo humano na teia urbanística. Essas transformações foram, de forma geral, agregadoras para os habitantes das cidades, a despeito de também Ihes terem trazido incertezas e injustiças.

Por meio de instrumentos historicamente construídos, o homem afirmou o seu direito de viver na cidade, de participar do seu planejamento, e de usufruir de direitos fundamentais que thes assegurem uma qualidade de vida digna, seja no meio urbano ou rural. Atualmente, as cidades modernas possuem funções sobrepostas como: habitar, trabalhar, passear entre outras, sendo que as funções privilegiadas na cidade pós-liberal são as produtivas, com destaque para as terciárias, como comércio e circulação.

Uma questão patente nas cidades contemporâneas é o fato de que os direitos e as benesses angariados em termos históricos não estariam disponíveis a todos. Além disso, no processo de formação dos centros urbanos houve transformações que trouxeram graves problemas sociais, como 
desigualdades; deficiência na prestação de serviços públicos; e inseguranças ligadas especificamente às questões urbanas.

O meio ambiente urbano é um mosaico irregular produzido pela atuação de agentes sociais no contexto da sociedade capitalista, cuja sobreposição do âmbito econômico determinou a formação de áreas e espaços estruturalmente hierarquizados. Elementos como a heterogeneidade de renda, o grau de instrução, a etnia, a qualidade das habitações, dentre outros, são determinantes e, ao mesmo tempo, produtos dessa segregação.

Nesse cenário brasileiro de desigualdade econômica, sócio-política e cultural, ampliam-se as áreas periféricas, num processo favelização e segregação espacial, com espaços urbanos estigmatizados e desvalorizados. Na prática, esse processo têm sido reproduzido e aprofundado ao longo dos anos, afastando-se eventuais políticas publicas que tragam maior sustentabilidade urbana para as presentes futuras gerações. Nesses termos, questiona-se, neste estudo, quais são os caminhos que levariam à consecução do direito à cidade sustentável?

Em resposta a essa questão-problema, iniciam-se as reflexões analisando-se o tema cidade $e$ complexidade, partindo-se do pressuposto de que a cidade vai além de seu aspecto físico e materialmente organizado. Ela representaria um sistema complexo, compreendendo relações entre pessoas e bens, moldando continuamente o processo de urbanização. Nesse sentido, a complexidade refere-se a uma visão interdisciplinar, que se oporia à ideia de simplificação, envolvendo fenômenos, ao mesmo tempo, complementares, concorrentes e antagonistas.

No segundo item do trabalho, tratar-se-á da segregação socioespacial no meio ambiente artificial, partindo-se de um movimento de impulso ao desenvolvimento nacional ocorrido na década de 1930, quando o Brasil passou por um processo de crescimento em razão de políticas públicas implantadas pelo governo Getúlio Vargas, intensificando um movimento migratório materializado no êxodo rural, que foi crucial para a relação socioespacial dos centros urbanos.

Nesse contexto, a segregação socioespacial foi sendo estabelecida nas cidades, contrariando a ideia de um espaço destinado às realizações coletivas, num movimento que atendeu aos interesses de grupos restritos que usufruíram dos poderes políticos e econômicos locais. Também a globalização, as mudanças na política econômica, a redução do papel do Estado, entre outros, representam fatores que modificaram as formas das cidades, gerando novas desigualdades, conflitos e um desenvolvimento desigual entre as classes.

No terceiro item, tratar-se-á do tema direito à cidade e injustiça socioambiental, assunto que atualmente vem sendo objeto de trabalho e reflexões nas universidades, em razão da sua importância e atualidade. Nesse cenário, aquela injustiça, que trata do problema da distribuição desigual dos riscos ambientais na sociedade, soma-se às desigualdades estabelecidas em outros âmbitos. 
Analisar-se-á, no quarto item deste artigo, alguns fatores que interferem na consecução do direito à cidade sustentável, previsto no Estatuto da Cidade, Lei no 10.257 de 2001 . Aqui, parte-se da ideia pautada na legislação nacional de que a política urbana brasileira deve ter por objetivo ordenar o pleno desenvolvimento das funções sociais da cidade e da propriedade urbana, mediante diretrizes gerais como a garantia do direito a cidades sustentáveis, entendido como o direito à terra urbana, à moradia, ao saneamento ambiental, à infra-estrutura urbana, ao transporte e aos serviços públicos, ao trabalho e ao lazer, para as presentes e futuras gerações.

Por fim, no presente artigo, realizar-se-ão reflexões sobre o direito à cidade sustentável em termos de criação de políticas públicas, de participação da sociedade civil, de formação de uma consciência crítica, a fim de que a qualidade de vida seja atingida de forma equitativa nos centros urbanos. Para o desenvolvimento do trabalho, utilizou-se o método de abordagem dedutivo, método de procedimento monográfico, com técnica de pesquisa bibliográfica.

\section{CIDADES E COMPLEXIDADE}

As cidades atualmente revelam-se como o cenário da vida da maioria das pessoas, seja em razão do êxodo rural ocorrido em décadas anteriores, seja pelos atrativos socioeconômicos e tecnológicos que incrementam a qualidade de vida e o bem-estar moderno, que se concentram nos centros urbanos.

$\mathrm{Na}$ era paleolítica, o ser humano não dominava as técnicas de cultivo e de pecuária, impossibilitando-o de ocupar o solo. Esta ocupação somente ocorreu na era neolítica (7.000 a 6.000 a.C.), momento em que o ser humano desenvolveu técnicas capazes de extrair seu sustento da terra, domesticando animais, por exemplo. Consequentemente, a sociedade passou se estabelecer em localidades fixas, dando origem a vilas e cidades.

Os primeiros grupos habitacionais se valeram de aspectos ecológicos para se fixarem no território, não apenas para facilitar a produção agrícola e pecuária, mas também como forma de defesa contra pretensos invasores (CARVALHO; RODRIGUES, 2016).

O ambiente construído pelos homens do paleolítico não passava de uma modificação superficial do ambiente natural - imenso e hostil - no qual o homem começou a mover-se. $\mathrm{O}$ abrigo era uma cavidade natural ou refúgio de peles sobre uma estrutura simples de madeira. Já na sociedade neolítica, deixou de ser mero abrigo na natureza para se transformar em projeto humano, o que compreende os terrenos para cultivo e não apenas para se apropriar dos alimentos (BENEVOLO, 2017).

Antes de ser local de trabalho e moradia, as cidades foram templos surgidos no terceiro milênio antes da era cristã, na região da Mesopotâmia. No local do cerimonial o homem transformava o seu espaço, definindo-o de forma permanente, apropriando-se materialmente e ritualmente deste. Assim, os 
templos se somaram aos canteiros de obras de irrigação e constituíram as primeiras marcas do desejo humano de modelar a natureza. Nestes termos, De Masi (2016 apud CARVALHO; RODRIGUES p. 11) destaca que

[...] não tardou até surgirem motivos para a formação de uma comunidade urbana mais politizada: a realização de grandes obras de infraestrutura (como a construção de grandes canais de irrigação) e a militarização para a defesa das terras foram alguns dos principais motivos para que se formassem estruturas sociais verticalizadas, com uma divisão de trabalho mais organizada, que não se restringia apenas a um grupo familiar, mas a todos que conviviam no mesmo território préurbano. Uma nova ordem social foi fundada. Surgiu a concepção de nação e de Estado, ideias que levariam todos os indivíduos a seguirem as mesmas leis, o mesmo código moral, a mesma religião, a mesma autoridade soberana. A cidade, estava, enfim, formada.

Os primeiros aldeamentos da antiguidade serviram de palco para que o homem ali se fixasse e produzisse. Foi a partir dessa fixação que a ideia de urbanização e cidade começou a ganhar forma, com o trabalho cotidiano e a exploração dos recursos naturais. Consequência desse processo foi a segregação de grande parte da população.

O mapa abaixo se refere ao grau de urbanização no país no ano de 2010, apresentando os índices em porcentagens. Coloca-se em discussão a relação das taxas de urbanização com eventuais violações ao direito à cidade sustentável, tendo em vista que o crescimento urbano se deu de forma rápida e desordenada no Brasil. Em razão disso, as cidades - e suas políticas públicas - não foram capazes de garantir direitos fundamentais aos seus habitantes de forma homogênea.

Figura 1: Grau de urbanização no Brasil (2010)

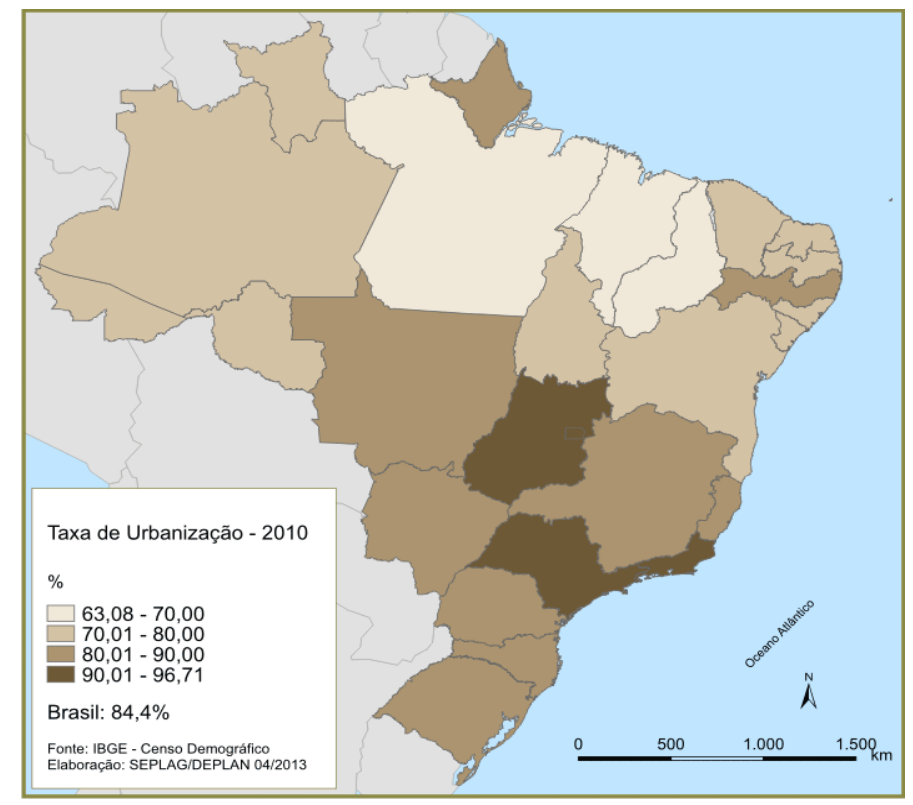

Fonte: IBGE, 2010.

Conforme informações contidas no Atlas Socioeconômico Rio Grande do Sul (2016), na década de 1960 o Brasil ainda era um país eminentemente agrícola. Sua taxa de urbanização era inferior a 45\%. A 
partir disso, como se pôde inferir do mapa acima, este índice está em constante crescimento, tendo atingido a marca de $84,4 \%$ em 2010.

Atualmente, as cidades modernas possuem funções sobrepostas como: habitar; trabalhar; cultivar o corpo e o espírito; e o circular. As funções privilegiadas na cidade pós-liberal são as produtivas, com destaque para as terciárias, como comércio e circulação. Contudo, a cidade moderna regularizada e pós-liberal não estaria disponível a todos, já que a população mundial se aglomera em cidades irregulares, que reproduzem em escala muito maior os estabelecimentos liberais do primeiro período industrial (BENEVOLO, 2017).

Segundo Harvey (2013), desde o início, as cidades surgiram nos lugares onde existe produção excedente, ou seja, a que excede as necessidades de subsistência de uma população. $O$ autor afirma que a urbanização sempre foi um fenômeno de classe, tendo em vista que o controle sobre o uso dessa "sobreprodução" sempre esteve nas mãos de poucos, como no regime feudal. Sob a égide do capitalismo, emergiu estreita conexão entre o desenvolvimento do sistema e a urbanização.

Esse processo de formação dos centros urbanos ensejou transformações que trouxeram graves problemas sociais: desigualdades; deficiência na prestação de serviços públicos; e inseguranças ligadas especificamente às questões urbanas. Hoje, a cidade apresenta diferentes funções, propiciando a existência inclusive de um vínculo espiritual entre os seres humanos e a cidade.

Sacconi (2010, p. 431), define a cidade como o "núcleo populacional e comercial denso e permanente, socialmente heterogêneo, mas altamente organizado, sede de município". Na sociedade brasileira, destaca-se o impasse relacionado ao fato de os citadinos figurarem como meros observadores da gestão do espaço público. Isto possibilita que este espaço seja dominado por ações de interesse exclusivo dos governantes, resultando em potenciais desigualdades sociais, a exemplo da segregação socioespacial (CAMERA; MACIEL, 2020).

No Brasil, cidade e município são expressões distintas para designar diferentes aspectos de um mesmo território. A cidade vai além de seu aspecto físico e materialmente organizado. Ela representa um sistema complexo, compreendendo relações entre pessoas e bens, em movimento incessante de urbanização. Esse fenômeno apresenta variações de acordo com a intensidade da ocupação e a transformação desse espaço pelo ser humano, o que inclui sua relação com o meio ambiente.

A vida de todos os seres vivos está atrelada à biosfera. Assim, o ser humano costuma ser definido como ser biológico, psíquico e cultural, segundo as ciências humanas. Ele seria, desta forma, ser complexo, não compartimentado, assim como a cidade.

A complexidade - teoria da complexidade ou pensamento complexo - é utilizada em várias áreas das ciências e sua definição costuma variar de acordo com a área de conhecimento. Normalmente, diz respeito a uma visão interdisciplinar, que se opõe à ideia de simplificação. O pensamento complexo 
partiria de fenômenos, ao mesmo tempo, complementares, concorrentes e antagonistas, respeitando as coerências diversas que se unem em dialógicas e polilógicas, enfrentando a contradição por várias vias (MORIN, 2005).

A perspectiva da complexidade visa permear e articular os saberes, para que a partir daí, se possa efetivar a compreensão do todo. A complexidade chama atenção para o respeito às diversas dimensões do ser. Parte da ideia de interdependência entre o homem e seu meio. Nesse contexto, o direito à cidade sustentável se coaduna perfeitamente ao pensamento complexo, já que o próprio meio ambiente, seu objeto, apresenta-se como entidade complexa, englobando diversas áreas do conhecimento.

O meio ambiente constitui conjunto de elementos (ecossistemas) que apresentam vínculos ou relações que se desenvolvem e se transformam ao longo dos tempos. Há complexidade nos elementos que compõem o ambiente, assim como há dependência mútua entre eles. A complexidade alinha-se à ideia de derrubar as fronteiras que separam as ciências, além da reunificação do conhecimento, considerado interdependente. Repensar o direito, a sociedade e a cidade é libertar o direito dos compartimentos que the foram impostos.

Tratando de problemas contemporâneos, incluindo-se os urbanos, Morin; Kern (2011) vêem o crescimento econômico como causa de novos desregramentos, o que contribuiria para a construção de problemas globais - como a contaminação das águas e lençóis freáticos; envenenamento dos solos por excesso de pesticidas e fertilizantes; urbanização maciça de regiões ecologicamente frágeis, como as zonas costeiras; desmatamento; inundações, entre outros. Os autores advertem que o desenvolvimento deveria ser concebido de maneira antropológica, e não exclusivamente econômica. Dever-se-ia objetivar o desenvolvimento humano, e não centralizar esse processo no viés econômico (MORIN; KERN, 2011).

Para Morin; Kern (2011, p. 100), "a noção de desenvolvimento deve tornar-se multidimensional, ultrapassar ou romper os esquemas não apenas econômicos, mas também civilizacionais e culturais ocidentais que pretendem fixar seu sentido e suas normas". Nesses termos, a finalidade do desenvolvimento deveria ser viver verdadeiramente, viver melhor, viver de modo a se privilegiar a compreensão, a solidariedade, a compaixão, viver com dignidade.

A política urbana também deveria tratar da multidimensionalidade dos problemas circunscritos à cidade, respondendo a problemas específicos, mas não os tratando de forma compartimentada e fragmentada. Ainda que a política guarde um caráter técnico e científico, ela não deve se submeter ao sistema da especialização que destrói o global, o fundamental e a responsabilidade (MORIN; KERN, 2011).

Assim, a fim de dar respostas aos atuais problemas relacionados à cidade, é fundamental que o pensamento não envolva noções separadas e saberes compartimentados. Na arena urbana contemporânea, há a necessidade de se enfrentar problemas que comportam incertezas e imprevisibilidades, interdependências e inter-retro-ações de extensão planetária relativamente rápida, 
com descontinuidades, não-linearidades, desequilíbrios, comportamentos "caóticos" e bifurcações (MORIN; KERN, 2011). Por essa razão, o direito à cidade deverá focar nessas novas diretrizes a fim de que se possa, de fato, adequar-se à atual realidade planetária e construir uma estratégia eficaz enquanto política pública urbana.

Por fim, o direito à cidade deve assumir uma perspectiva complexa, materializando-se tanto como determinação normativa, quanto como uma oportunidade de melhor lidar com a realidade das cidades, ou seja: uma realidade que apresenta crises e precariedades em todos os âmbitos, e que precisa de resposta adequada, de modo que atinja bons efeitos no futuro.

\section{A SEGREGAÇÃO SOCIOESPACIAL NO MEIO AMBIENTE ARTIFICIAL}

A partir da década de 1930, o Brasil passou por um processo de desenvolvimento em razão de políticas públicas implantadas pelo governo Getúlio Vargas, em cenário ainda de impulso econômico promovido pela Revolução Industrial. Nessa época, a relação entre cidade e campo foi significativamente alterada pelo grande contingente migratório em direção aos centros urbanos, sobretudo em busca de trabalho. Nesse sentido, Carvalho; Rodrigues (2016, p. 15) comentam que

A imagem do progresso advinda das grandes cidades foi fundamental para aplacar o desespero dos homens, que abandonavam o campo por falta de oportunidades, já que a produção rural foi fundamentalmente mecanizada. O resultado destas migrações se fez sentir intensamente. Entre 1800 e 1950, a população mundial se multiplicou por dois e meio, enquanto a população urbana se multiplicou por vinte [...].

Esse movimento migratório interferiu na relação socioespacial e seus efeitos se perpetuam até os dias atuais. Com o avanço do processo de industrialização, maior foi o êxodo rural. O homem do campo ficou cada vez mais isolado, privado também de políticas públicas que o auxiliasse na superação de suas dificuldades diárias. Sobre esse ponto, Lefebvre (2001, p. 74) destaca que

[...] a relação cidade-campo se transforma, aspecto importante de uma mutação geral. Nos países industriais, a velha exploração do campo circundante pela cidade, centro de acumulação do capital, cede lugar a formas mais sutis de dominação e de exploração, tornando-se a cidade um centro de decisão e aparentemente de associação. Seja o que for, a cidade em expansão ataca o campo, corrói-o, dissolveo. Não sem os efeitos paradoxais anteriormente observados. A vida urbana penetra na vida camponesa despojando-a de elementos tradicionais: artesanato, pequenos centros que definham em proveito dos centros urbanos (comerciais e industriais, redes de distribuição, centros de decisão, etc.). As aldeias se ruralizam perdendo a especificidade camponesa. Alinham-se com a cidade, porém resistindo-a às vezes, dobrando-se ferozmente sobre si mesmas. 
Nesse sentido, a cidade absorveu o campo, ainda que isso tenha ocorrido de maneira heterogênea, em um movimento de segregação socioespacial. Isto pois os habitantes do campo não dispunham da mesma atenção encontrada e concentrada atualmente nos centros urbanos.

Contudo, a referida segregação socioespacial também está presente no interior das cidades, contrariando a ideia de um espaço destinado às realizações coletivas, já que, de fato, deu lugar ao atendimento de interesses de grupos restritos que usufruem dos poderes políticos e econômicos locais.

Assim, a cidade tornou-se um território de exploração do capital (ou da força de trabalho), um negócio lucrativo para especulações e perpetuação de poder; um lugar com acesso restrito à cidadania. A realidade das cidades permaneceu fluida, sendo construída e reconstruída a todo instante de acordo com interesses políticos, econômicos e culturais que pertencem a uma minoria (CARVALHO; RODRIGUES, 2016, p. 20). Nesse ponto, Carlos et al. (2017, p. 138) explicam que

A segregação sócio-espacial e sua forma mais avançada e complexa de expressão, a fragmentação sócio-espacial, são, contraditoriamente, os processos que negam e redefinem a centralidade. Transformam-na em centralidade segmentada social e funcionalmente, dispersa no território e difusa na representação que elaboramos sobre a própria cidade e sobre a rede urbana, visto que a centralidade pode ser compreendida e apreendida em múltiplas escalas.

A economia política típica das cidades gerou estruturas espaciais mais complexas, possibilitando o acesso à cidade pela propriedade. Muitos ainda buscam essa forma de apropriação de espaço, o que revela e produz, na prática, enorme desigualdade socioespacial (CARLOS et al., 2017).

Processos mais amplos como globalização, mudanças de economia, redução do papel do Estado, migrações nacionais e internacionais, além dos movimentos sociais, são fatores que modificaram as formas das cidades, gerando novas desigualdades, sem conseguir eliminar conflitos raciais, religiosos, políticos, entre outros. (VASCONCELOS, 2016).

Em âmbito internacional, o direito à cidade foi abordado em documentos técnicos para fundamentar a Nova Agenda Urbana (NAU) para a Conferência Habitat III, como elemento da Policy Unit I. A Terceira Conferência das Nações Unidas sobre Moradia e Desenvolvimento Urbano Sustentável, foi realizada em Quito, no Equador. Entre as principais disposições do documento, estão a igualdade de oportunidades para todos; o fim da discriminação; a importância das cidades mais limpas; a redução das emissões de carbono; o respeito pleno aos direitos dos refugiados e migrantes; a implementação de melhores iniciativas verdes e de conectividade, entre outras (ONU, 2016).

Ressalta-se no documento que a sua efetivação implica uma aliança estratégica em diversos níveis e escalas, do local ao global. O Policy Unit I faz recomendações para as cidades do mundo, assentando-se no entendimento de que as cidades são bem comum e devem ser livres de discriminação, com inclusão cidadã e participação política; cumprindo sua função social; com espaços públicos; respeito à igualdade 
de gênero, à diversidade cultural e ao meio ambiente; e com economia inclusiva (KLUG; AMANAJÁS, 2018).

No Brasil, o Estatuto da Cidade (Lei no 10.257 de 2001) conferiu especial importância aos planos diretores como principal instrumento de efetivação do direito à cidade, além de ter criado diversos institutos jurídicos e políticos, visando combater processos causadores de desigualdades urbanas, como parcelamento, edificação e utilização compulsórios. Dentre os institutos, pode-se citar o Imposto Predial e Territorial Urbano (IPTU) progressivo no tempo com desapropriação mediante pagamento em títulos da dívida pública; a outorga onerosa do direito de construir e de alteração de uso; a transferência do direito de construir, entre outros.

Contudo, no Brasil, o reconhecimento legal e institucional do direito à cidade contrasta com a realidade urbana cotidiana de negação de direitos, em especial, aos "invisíveis" ao processo de planejamento e produção do espaço urbano. Fatores como gênero, raça, idade, etnicidade e renda distribuem desigualmente os ônus e os benefícios da urbanização entre os indivíduos no território (KLUG; AMANAJÁS, 2018).

Assim, perpetua-se uma segregação na cidade capitalista, que emerge da localização diferenciada do espaço urbano de distintas classes sociais e suas frações. Quanto mais intensa a fragmentação social, mais complexa será a segregação. Esse fenômeno apresenta aspectos de auto-segregação e de segregação imposta. Aquela está relacionada a uma política de classe associada à elite e de estratos superiores da classe média, com renda elevada, reproduzindo desigualdades que se vê atualmente no setor de moradia. Já a segregação imposta é efetivada de forma explícita. Se expulsa à força para uma limpeza social. Normas urbanísticas e tributação diferenciada no espaço urbano ajudam a manter essa imposição da segregação (CORRÊA, 2016).

Assim, a prática espacial urbana manifesta extrema separação dos elementos que sustentam a vida. Destaca-se a relevante divisão entre os locais de moradia e trabalho, que se relaciona à "separação casa-lazer" (CARLOS, 2020. p. 355). Portanto, "a vida cotidiana revela-se, assim pela fragmentação dos elementos da prática socioespacial urbana em espaços-tempos separados enquanto elementos autônomos da vida" (CARLOS, 2020).

Por fim, a segregação socioespacial não se apresenta como resultado de um único elemento, mas de diversos fatores que the dão uma dinâmica complexa. Há fatores que envolvem relações entre os centros urbanos e as periferias, o aspecto econômico e trabalhista, bem como questões envolvendo mão de obra e políticas públicas. Estes fatores são elaborados a partir de grupos hegemônicos, de auto segregação. Enfim, são múltiplas as formas de segregação socioespacial presentes nos centros urbanos, que envolvem aspectos ambientais, empresariais e educacionais. 


\section{Direito à Cidade e a Injustiça Socioambiental}

As transformações históricas ocorridas no meio ambiente urbano exigiram uma mudança comportamental do ser humano. Segundo Gonçalves Junior (2017, p. 71),

[...] O fenômeno do "êxodo rural" e das migrações fizeram das cidades grandes centros de convivência, com todos os seus conhecidos problemas, como: aumento populacional, meios de transporte e de saúde deficitários, serviços públicos insuficientes e com altas taxas de corrupção, criminalidade elevada, más condições de moradia, etc.

Ao comentar os graves problemas urbanos e a relação do homem com a cidade, Goldman (1970) afirma que o ser humano vive um estado de insignificância na grande cidade, tendo sido despersonalizado e ficando absorvido pelo ritmo coletivo dos grandes centros urbanos.

A formação de guetos, assim, seria fruto dessa "neurose" urbana que, ao lado da riqueza educacional e cultural, apresenta um viés de delinquência, alcoolismo, crimes, prostituições e insegurança. Para o autor (GOLDMAN, 1970, p. 53-58), o acelerado processo industrial e comercial alterou consideravelmente as formas e os costumes sociais. Nesses termos, o homem viveria envolto à ansiedade dos congestionamentos, ao desperdício de tempo, ao barulho e à fumaça das fábricas.

A Revolução Industrial e Comercial impulsionou as populações para os centros urbanos. A ampla atividade econômica, a rigidez das estruturas e organizações e a disponibilidade de bens e serviços também significaram a intensificação da desigualdade e a divisão rígida de classes, status e gêneros. Após aquelas revoluções, houve desenvolvimento desigual entre as classes, gerando um "planeta de favelas", com estendida pobreza e ausência de indústrias (GOUCHER; WALTON, 2011).

Apesar de todos esses problemas, a cidade ainda concentra esforços e é palco do avanço da ciência; do aumento da expectativa de vida; da grande quantidade de informações que o homem dispõe todos os dias através das tecnologias de informação e comunicação; e de avanços nos meios de transporte e serviços em geral. Nesses termos, falar de direito à cidade seria atribuir e conferir aos seus habitantes o direito de lutar por aquilo que ainda hoje não lhe é acessível, ou ainda lhe é negado.

Foi na obra de Lefebvre "Le droit à laville", que a teoria do direito à cidade foi apresentada originalmente. Na obra, o autor analisa, de forma crítica, como o sistema econômico capitalista influi sobre os espaços urbanos. Desde então, o direito à cidade traz a ideia de reivindicação do direito à vida urbana sob uma nova centralidade, que envolve o direito de criação e plena fruição dos espaços urbanos por múltiplos agentes sociais (DIAS; ALBUQUERQUE, 2019).

Entre a socialização da sociedade e a segregação generalizada, surgiram direitos em relação à cidade. Direitos concretos que complementam direitos abstratos; direitos das idades dos sexos (aqueles 
que envolvem a mulher, a criança e os idosos); direito das condições (o proletário e o camponês); direito à instrução e à educação; direito ao trabalho, à cultura, ao repouso, à saúde e à habitação (LEFEBVRE, 2001).

Contudo, atualmente, as leis urbanísticas não beneficiam a todos de forma igualitária, ou ao menos de forma aproximada, o que resulta em imensa massa de excluídos vivendo nas cidades. Nessa esteira, Carvalho; Rodrigues, (2016, p. 30) comentam que

As leis urbanísticas costumam regulamentar modelos de uso e ocupação do solo que só são possíveis de serem observados pelos que detêm condições econômicas privilegiadas ou pelo menos remediadas. Para um grande número de habitantes de baixa renda que tentam sobreviver na cidade, resta a ilegalidade. Resta a favela, a invasão, o cortiço irregular, a ocupação ilegal. Em nenhum momento eles foram banidos da cidade, pois o modelo capitalista vigente nos países da periferia precisa dessa mão de obra barata o bastante para evitar gastar dinheiro com residências regulares ou com outras benesses. $O$ sistema precisa que eles continuem na cidade - ou melhor, à margem da cidade - de modo que estes indivíduos só deverão ser removidos dali se algum interesse imobiliário passar a admirar aquelas redondezas. Caso isso ocorra, eles serão transferidos para uma periferia recém-inventada.

A questão da desigualdade e da exclusão leva a outro tema de extrema relevância que é a chamada justiça ambiental, tema esse que se estabeleceu na década de 1980 e que, atualmente, vem sendo objeto de trabalho e reflexões nas universidades, em razão da sua importância e atualidade. Aquela justiça trata do problema da distribuição desigual dos riscos ambientais na sociedade.

Pesquisas atuais demonstram que pessoas ou comunidades que suportam riscos ambientais maiores - como as que residem próximas a lixões ou aterros tóxicos - são normalmente aquelas que possuem baixa renda e baixa escolaridade. Cuida-se, dessa forma, de um tipo de racismo que se refere, fundamentalmente, à discriminação atrelada a um grupo de pessoas em razão de sua condição social e de sua etnia.

Acselrad et al., "(2009) explicam que a noção de justiça ambiental significa o direito a um meio ambiente seguro, sadio e produtivo para todos, onde o "meio ambiente" deve ser visto em sua totalidade, englobando todas as suas dimensões. Significa que tal direito deve ser livremente exercido, preservando, respeitando e realizando plenamente as identidades individuais e coletivas.

Observa-se que a desigualdade ambiental pode se manifestar tanto sob a forma de proteção ambiental desigual, como pelo acesso desigual aos recursos ambientais. A proteção desigual dá-se com relação à não implementação de políticas públicas ambientais, causando riscos intencionais e/ou locais, para a população mais vulnerável e carente (em regra).

As causas da referida desigualdade são normalmente atribuídas: ao mercado (por meio de empresas poluidoras que se locomovem e instalam-se com certa facilidade em países em desenvolvimento, por exemplo); às ações ou omissões políticas, como as omissões políticas governamentais 
na instalação de grandes empreendimentos poluidores; à desinformação, já que os riscos e perigos são geralmente ocultados, causando, com isso, retrocesso aos direitos mínimos, sobretudo àqueles ligados ao exercício da cidadania e ao acesso ao poder público e ao Poder Judiciário; e à corrupção endereçada ao poder público local e às populações, normalmente de baixa renda, com o propósito de evitar ações ou críticas que eventualmente possam ser pertinentes em razão de instalação de empresa ou empreendimento que cause importante impacto ambiental (ACSELRAD et al., 2009).

Nesses termos, a construção de uma concepção de justiça ambiental deve congregar proteção do meio ambiente e a manutenção dos direitos humanos e fundamentais. É aqui que tal concepção se coaduna ao direito à cidade sustentável, fazendo-se necessário o estabelecimento de políticas públicas e legislativas que respeitem a distribuição equilibrada dos riscos ambientais, sem discriminação em função de variáveis como classe social, etnia e gênero, por exemplo.

O mapa a seguir apresenta o mapa de injustiças ambientais no país, apresentando o mapeamento dos casos de conflitos ambientais em alguns dos estados brasileiros, com potencial de violação dos direitos humanos, e, consequentemente, aptos a prejudicar o desenvolvimento de um ambiente urbano sustentável.

Figura 2: Mapa de Injustiças Ambientais no Brasil

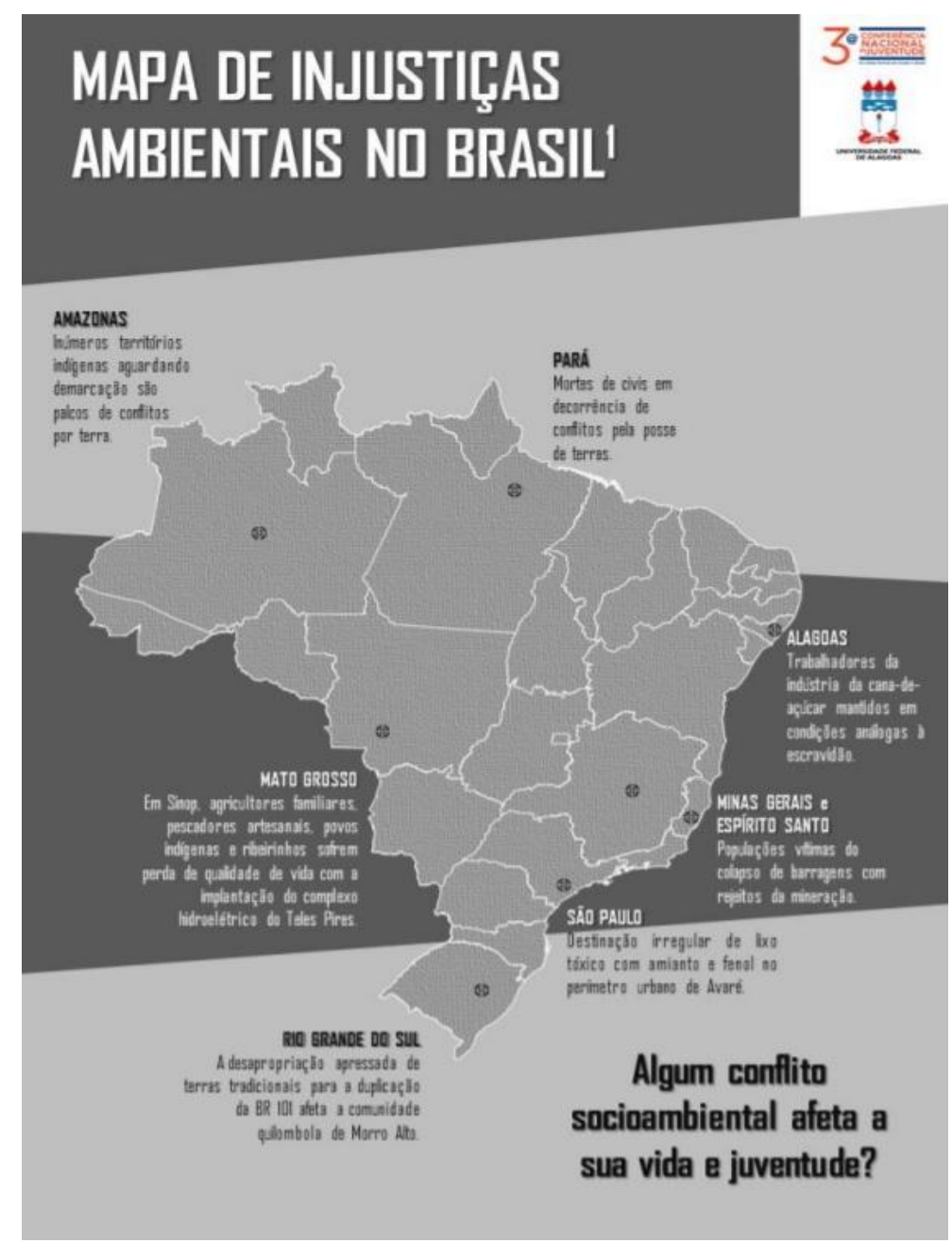

Fonte: Correia, 2017. 
Assim, observa-se que os conflitos socioambientais, que originam grandes injustiças ambientais, estão presentes em todas as regiões do país. No estado do Amazonas, por exemplo, territórios indígenas aguardam demarcação e são palcos de conflitos pelo uso da terra. Em Minas Gerais e no Espírito Santo, populações são vítimas de desastres ambientais envolvendo barragens com rejeitos da mineração.

As transformações na cidade não resultam passivamente da globalidade social, mas dependem essencialmente das relações diretas entre pessoas e grupos que a compõem, como famílias, corpos organizados, profissões, corporações, entre outros. A cidade se coloca num meio termo, entre uma ordem próxima (composta por relações individuais e de grupos mais ou menos organizados e estruturados), e uma ordem distante (formada por grandes e poderosas instituições, como a Igreja e o Estado), regida por um código jurídico que permite que essa ordem distante se projete na realidade prático-sensível, e que a cidade reproduza seus anseios (LEFEBVRE, 2001).

No mesmo sentido, a diferença nos graus de exposição das populações aos males ambientais não decorre de nenhuma condição natural, determinação geográfica ou casualidade histórica, mas de processos sociais e políticos que distribuem de forma desigual a proteção ambiental. Nesse contexto, a pobreza apresentar-se-ia como efeito ou resultado de um processo social determinado (ACSELRAD, et al., 2009).

Assim, o direito à cidade vincula-se à ideia de cidadania, direito à informação, à expressão, à cultura, aos serviços, entre outros. Trata-se de direito que deve ser acessível a todos, pois abrange, sobretudo, uma série de direitos fundamentais. Um amplo acesso é que trará equidade em termos socioambientais.

A justiça distributiva condena o acúmulo de poder e a formação de um poder paralelo que concorre com o próprio Estado Democrático de Direito. O caráter humanizador do direito deve predominar sobre os aspectos econômicos que movimentam as cidades e só fortalecem um pequeno grupo de pessoas.

De acordo com Dias-Parra e Jover (2020, p. 12), “Mecanismos de mercantilização e gentrificação contribuem para injustiças socioespaciais e também tornam a cidade "inautêntica" para visitantes e moradores. Nesse sentido, o direito de viver e aproveitar a cidade é perdido para ambos os grupos".

Por fim, a desigualdade socioambiental, que denota a injustiça ambiental, requer o fortalecimento das instituições democráticas, sobretudo no Brasil, país fortemente marcado por desigualdades e injustiças de caráter geral, que necessita de ações e/ou reações tanto do Estado, quanto da sociedade civil organizada, a fim de que se reverta o atual processo.

Nesse contexto, o direito à cidade sustentável poderá representar um instrumento valioso para a promoção da justiça ambiental no país, já que esta tem por objetivo incorporar e multiplicar a informação e, por consequência, fortalecer os princípios ligados à atuação cidadã. Assim, aquele direito assume 
relevância como reforço à diminuição das desigualdades e injustiças, sociais e ambientais, que assolam o país.

\section{O DIREITO À CIDADE SUSTENTÁVEL}

O Estatuto da Cidade (Lei 10.257/2001) regulamenta os artigos relativos à política urbana no âmbito federal (arts. 182 e 183 da atual Constituição Federal), prevê o direito à cidade em seu art. 2으, incisos I e II, que dispõem sobre o direito a cidades sustentáveis. Nesses termos, a política urbana brasileira deve ter por objetivo ordenar o pleno desenvolvimento das funções sociais da cidade e da propriedade urbana, mediante diretrizes gerais como a garantia do direito a cidades sustentáveis, entendido como o direito à terra urbana, à moradia, ao saneamento ambiental, à infra-estrutura urbana, ao transporte e aos serviços públicos, ao trabalho e ao lazer, para as presentes e futuras gerações.

Conforme o art. 2으, II do Estatuto da Cidade, a política urbana brasileira ainda deverá se dar por meio de gestão democrática, com participação da população e de associações representativas dos vários segmentos da comunidade na formulação, execução e acompanhamento de planos, programas e projetos de desenvolvimento urbano.

$\mathrm{O}$ art. 2ㅇ, VIII, estabelece que a política urbana tem por objetivo ordenar o pleno desenvolvimento das funções sociais da cidade e da propriedade urbana mediante diretrizes gerais, como a adoção de padrões de produção e consumo de bens e serviços e de expansão urbana compatíveis com os limites da sustentabilidade ambiental, social e econômica do Município e do território sob sua área de influência.

Klug; Amanajás (2018) definem o direito à cidade como difuso e coletivo, de natureza indivisível, de que são titulares todos os habitantes da cidade, além das gerações presentes e futuras. Para as autoras, trata-se de "Direito de habitar, usar e participar da produção de cidades justas, inclusivas, democráticas e sustentáveis." (KLUG; AMANAJÁS, 2018, p. 19) Completam com a ideia de que "a interpretação do direito à cidade deve ocorrer à luz da garantia e da promoção dos direitos humanos, compreendendo os direitos civis, políticos, sociais, econômicos e culturais reconhecidos internacionalmente a todos."

Nesse sentido, atendendo à complexidade do conceito exposto, a busca por cidades sustentáveis requer a superação dos problemas de ordem social, política, cultural, econômica e ambiental que se experimentam atualmente. Diante dos recursos finitos, o homem precisa se reinventar cotidianamente buscando alternativas para melhor viver em sociedade.

Uma das alternativas buscadas pelo modelo de cidade sustentável é o fomento à utilização de meios de transporte coletivos e/ou sustentáveis. Para isso, mostra-se imprescindível o fornecimento de serviços de transporte de acesso equitativo a todos os cidadãos. Estas transformações passam pela priorização de transporte para pedestres e públicos em vez de veículos particulares. A cidade de Jacarta, 
no Sudeste Asiático, estabeleceu esta política a fim de aprimorar seu planejamento urbano à luz do desenvolvimento sustentável (HIDAYATI, et. al., 2019).

Além disso, um dos grandes obstáculos a ser transposto atualmente é o consumismo, ou seja, o excessivo gasto em bens, sem a sua real necessidade. Sobre esse ponto, Harvey (2013) comenta que a expansão mais recente do processo de urbanização trouxe consigo mudanças incríveis no estilo de vida, em que a qualidade da vida nas cidades virou uma mercadoria, em um mundo onde o consumismo, o turismo e as indústrias culturais e do conhecimento se tornaram aspectos importantes da economia urbana.

Para o autor, "a tendência pós-modernista de incentivar a formação de nichos de mercado, nos hábitos de consumo e nas expressões culturais, envolve a experiência urbana contemporânea numa aura de liberdade de escolha - desde que se tenha dinheiro." (HARVEY, 2013, p. 20) Nessa esteira, nas cidades brotam os shoppings centers, cinemas multiplex, lojas padronizadas, lojas artesanais, lanchonetes, entre outros.

Nesse contexto, a concepção de sustentabilidade deve ser objetivo permanente, já que a sociedade cresce numa proporção quantitativamente superior à disponibilidade dos recursos encontrados na natureza (HARVEY, 2013). Numa sociedade marcada pelo consumismo, a busca pelo "ter", e não pelo desenvolvimento do ser, tem custado caro ao meio ambiente. A sustentabilidade - estampada em planos, metas, critérios e normas - vem sendo negligenciada pelo Estado e pela sociedade em geral. Em meio a desigualdades e segregações, estaríamos vivendo, cada vez mais, em áreas urbanas divididas e propensas a conflitos.

De acordo com Veiga (2010), a expressão sustentabilidade evoca, em última instância, uma espécie de "ética de perpetuação da humanidade e da vida", passando a exprimir a necessidade de um uso mais responsável dos recursos ambientais. Isto conflita, de certa forma, com correntes de pensamento utilitaristas e individualistas, a exemplo da economia neoclássica, cuja racionalidade é a maximização das utilidades individuais com a resultante determinação do uso "ótimo" ou "eficiente" dos recursos.

De outro vértice, Machado (2016) vê a sustentabilidade como princípio, cujos critérios fundantes seriam: 1) a análise das ações humanas quanto à incidência de seus efeitos no tempo cronológico, tendo em vista estes residirem tanto no presente quanto no futuro; e 2) a análise da continuidade e das consequências da duração desses efeitos, visando a um prognóstico do futuro.

A partir disso, nota-se uma característica da sustentabilidade, ou seja: a preocupação com as consequências das ações humanas no presente e no futuro. Esta preocupação não se dá apenas a título de registro, mas direcionada a alcançar um equilíbrio. É nesse ponto que se torna imprescindível a compreensão do caráter pluridimensional ou multidimensional da sustentabilidade. 
Enquanto princípio, o termo sustentabilidade tem por finalidade alcançar a realização de um valor considerado supremo pelo legislador constituinte, denominado bem-estar. Embora seu conteúdo seja indeterminado, não é indeterminável, na medida em que é possível descartar o que não pode (e não pode) ser considerado como bem-estar. O conteúdo de bem-estar pode ser mais concreto, se analisada a realização do direito fundamental à saúde, por exemplo.

Nesse ponto, questiona-se a possibilidade de os indivíduos gozarem de bem-estar em sociedade onde não haja o devido respeito a uma ética, ao menos nacionalmente universalizável. Seria possível, ou louvável, viver bem em um ambiente degradado, poluído, em condições climáticas alteradas em razão de ações humanas? Uma sociedade que não cresce economicamente, onde as desigualdades fazem parte dos seus aspectos mais marcantes, pode subsistir soberanamente? Pode-se viver em uma sociedade em que as normas são apenas disposições abstratas sem aplicação concreta e destituídas de eficácia? Nesses termos, Freitas (2012) afirma que a sustentabilidade é multidimensional, porque o bem-estar é multidimensional.

Assim, o termo sustentabilidade apresenta-se como conceito aberto, devendo ser construído em termos práticos e teóricos no caso concreto. Ainda assim, a sustentabilidade pode ser compreendida, em última análise, como princípio constitucional, previsto no art. 225, da Constituição Federal, pelo qual se busca assegurar o bem-estar, em todas as suas dimensões, conjunta e equilibradamente, de modo a não impedir que este seja gozado no futuro pelas próximas gerações.

Em razão disso, a individualização da dimensão ambiental da sustentabilidade se dá tão somente para fins didáticos, vez que as dimensões deste princípio são indissociáveis. Nesses termos, a sustentabilidade ambiental pode ser entendida como o princípio que demanda uma situação de equilíbrio dinâmico das ações humanas com o natural equilíbrio do meio ambiente, em que a capacidade de recuperação deste não é ultrapassada pela exploração dos recursos naturais no decurso do tempo de uma geração à seguinte, permitindo-se, com isso, um bem-estar duradouro (EMERY).

A finalidade da sustentabilidade ambiental é a manutenção das condições de vida no planeta, de forma que as futuras gerações tenham o mesmo nível de biodiversidade e bem-estar que as presentes. A ideia de sustentabilidade ambiental procura trazer ao ser humano a consciência de que ele não está dissociado do meio ambiente, mas nele contido, ainda que dotado de atributos exclusivos em relação às demais espécies de seres vivos.

Nesse contexto, a economia e a preservação ambiental devem ser analisadas de forma conjunta. A busca por cidades sustentáveis deverá ser ponto fundamental na inversão da segregação socioespacial. A relação entre o ser humano, a cidade e o meio ambiente é tão importante que hoje se pode falar numa função socioambiental das cidades. 
Os Planos Diretores, o Estatuto da Cidade e os Estudos de Impactos Ambientais são instrumentos cada vez mais importantes na busca pela sustentabilidade urbana. Nesse processo, deve-se priorizar o planejamento urbano e se desenhar uma articulação estatal eficiente no cumprimento dessa tarefa. 0 desafio é reformular o conceito de interesse público, viabilizando-o através da ação do Estado. Conforme Bodnar et al. (2019, p. 49)

Revela-se, o planejamento urbano, genuíno processo de desenvolvimento socioespacial quando se verifica aperfeiçoamento da qualidade de vida e acréscimo de justiça social. A transformação social positiva inclui o lugar, ou seja: o espaço vivido e dotado de valor. Não se trata, portanto, apenas de desenvolvimento social, mas inclui a arena da vida e o referencial identitário das pessoas.

Na prática, a urbanização desempenha papel fundamental no reinvestimento dos lucros, em escala geográfica crescente. Por outro lado, cria fortes processos de destruição criativa que espoliaram as massas de qualquer direito à cidade, em um modelo onde "o planeta como canteiro de obras se choca com o 'planeta das favelas'” (HARVEY, 2013, p. 28).

Mas o que seria uma cidade sustentável? Seria possível utilizar essa terminologia nos dias atuais, sabendo dos grandes desafios que se tem de enfrentar em nível social e individual? Acredita-se que sim, tendo em vista a existência de legislação correspondente e de mecanismos que podem ser aplicados para que esse objetivo seja alcançado. Porém, isso só seria possível a partir da mudança de comportamento por parte da sociedade civil e do Poder Público. Em relação à ideia de cidade sustentável, Canepa (2007, p. 155-156) ensina que se trata de

(...) uma cidade onde as realizações e os avanços em desenvolvimento social, econômico e físico são feitos para durar. Uma Cidade Sustentável possui uma reserva durável de recursos naturais dos quais depende o desenvolvimento (utilizando-os somente num nível de produção sustentável). Uma Cidade Sustentável mantém uma segurança durável diante de desastres naturais que possam ameaçar o desenvolvimento (permitindo-se somente riscos aceitáveis). Cidades Sustentáveis são fundamentais para o desenvolvimento social e econômico.

Apesar dos diferentes conceitos apresentados, tudo indica que a relação homem-cidade ou homem-natureza deverá perseguir um equilíbrio entre o que a cidade/natureza pode oferecer e o que poderá ser disponibilizado por elas. Nesses termos, Rech; Rech $(2016$, p. 53) afirmam que

O equilíbrio, ou a sustentabilidade, não é uma invenção humana ou do Direito, mas é um princípio de direito imanente à própria natureza, que se revela como regra fundamental e obrigatória, sob pena de violação do próprio ciclo. A violação das leis da natureza gera degradação ambiental, cidades alagadas, sem água, sem verde, com saúde comprometida, qualidade de vida e sem sustentabilidade. A força e a perfeição das leis da natureza se constituem em algo que está distante da capacidade humana de fazer igual. Na realidade, a natureza cuida de tudo, e o melhor que se tem a fazer é não atrapalhar e não tentar controlá-la, mas sempre respeitá-la. (RECH, 2016, p. 53). 
Assim, o direito à cidade sustentável deverá considerar a complexidade que caracteriza as cidades e, a partir desse cenário complexo e multifacetado, dever-se-á realizar a sustentabilidade por meio dos instrumentos já presentes nos documentos legislativos nacionais, como o próprio Estatuto da Cidade e as principais leis ambientais atualmente em vigor. Nesse processo, é imprescindível que haja maior controle democrático sobre a produção e a utilização do lucro no palco dos centros urbanos.

Nesse ponto, Harvey (2013) explica que como o processo urbano é um dos principais canais de uso do dinheiro. Assim, a criação de uma gestão democrática da sua aplicação constituiria o próprio direito à cidade. Para o autor (HARVEY, 2013, p. 29), "ao longo de toda a história do capitalismo, uma parte do lucro foi tributada, e em fases social-democratas a proporção à disposição do Estado aumentou significativamente. O projeto neoliberal dos últimos trinta anos caminhou para privatizar esse controle." Harvey (2013) destaca que a principal conquista neoliberal foi evitar que a parcela pública se ampliasse. Criaram-se novos sistemas de governança que integraram os interesses estatais e empresariais, garantindo-se que os projetos governamentais para as cidades favoreçam as grandes empresas e as classes mais altas.

Nesse caso, "aumentar a proporção do dinheiro em poder do Estado só terá um impacto positivo se o próprio Estado voltar a ficar sob controle democrático." (HARVEY, 2013, p. 29) O autor ainda afirma que é crucial que se adote o direito à cidade, como slogan e como ideal político, já que tal direito levanta a questão de quem comanda a relação entre a urbanização e a produção do lucro. Para Harvey (2013, p. 31) "a democratização desse direito, e a construção de um amplo movimento social para fazer valer a sua vontade são imperativas para que os despossuídos possam retomar o controle que por tanto tempo lhes foi negado, e instituir novas formas de urbanização."

Finalmente, a busca por cidades sustentáveis é fundamental para o desenvolvimento social e econômico do país. Por isso, destaca-se a importância de o Estado melhor estruturar o seu poder regulador com relação ao capital das cidades, a fim de que este não se perpetue em benefício de poucos integrantes da elite, aumentando, dessa forma, o desequilíbrio e as desigualdades nos centros urbanos.

Uma alteração no modus operandi do sistema econômico deverá ter o propósito de conquistar maior distribuição de riquezas, fomentando o surgimento de um modelo de urbanização e a participação democrática nas cidades. Nesse sentido, a cidade deve iniciar um processo de transformação, mediante a construção de um programa político de reforma urbana onde o controle do desenvolvimento urbano não seja essencialmente coordenado pelo capital, mas em atendimento às necessidades e anseios da população. 


\section{CONSIDERAÇÕES FINAIS}

A perspectiva da complexidade parte da ideia de interdependência entre o homem e seu meio. Nesse contexto, o direito à cidade sustentável se coaduna perfeitamente ao pensamento complexo, já que o próprio meio ambiente, seu objeto, apresenta-se como entidade complexa, englobando diversas áreas do conhecimento. Nesse liame, a política urbana deveria tratar da multidimensionalidade dos problemas circunscritos à cidade, respondendo a problemas específicos, não os tratando de forma compartimentada e fragmentada, a fim de não se perpetuar uma segregação no meio urbano.

Hoje, vivencia-se um período de insustentabilidade urbana, pois a maior parte das cidades brasileiras ainda carece de um controle adequado sobre as questões socioambientais. Isso tem origem no precário planejamento urbano, num contexto em que os cidadãos que habitam a cidade ainda figuram como observadores passivos da gestão do espaço público, o que propicia que este espaço seja palco de ações de interesse quase exclusivo de governantes aliados a atores privados do setor imobiliário.

A segregação socioespacial se apresenta como resultado de diversos fatores que the dão uma dinâmica complexa. Essa dinâmica dá ensejo a padrões normativo-comportamentais elaborados a partir de grupos hegemônicos, propagando-se múltiplas formas de segregação socioespacial nos centros urbanos, que envolvem aspectos ambientais, empresariais e educacionais.

A diferença nos graus de exposição das populações aos males ambientais não decorre de nenhuma condição natural, determinação geográfica ou casualidade histórica, mas de processos sociais e políticos que distribuem de forma desigual a proteção ambiental. Nesse contexto, a pobreza apresentase como efeito ou resultado de um processo social determinado.

A desigualdade socioambiental, que denota a injustiça ambiental, requer o fortalecimento das instituições democráticas, sobretudo no Brasil, país fortemente marcado por desigualdades e injustiças de caráter geral, que necessita de ações e/ou reações tanto do Estado, quanto da sociedade civil organizada, a fim de que se reverta o atual processo. O direito à cidade sustentável poderá representar um instrumento valioso para a promoção da justiça ambiental no país, já que esta tem por objetivo incorporar e multiplicar a informação e, por consequência, fortalecer os princípios ligados à atuação cidadã.

Nesse sentido, dever-se-á realizar a sustentabilidade por meio dos instrumentos já presentes nos documentos legislativos nacionais, como o próprio Estatuto da Cidade e as principais leis ambientais atualmente em vigor.

Contudo, na prática, o modelo neoliberal capitalista segue privilegiando pequena parcela da população, com um processo de distribuição de renda e geração de riquezas não equitativos. A segregação no meio ambiente urbano se apresenta sob várias formas: sob o ponto de vista econômico, 
cultural, político, entre outros. $\mathrm{O}$ projeto neoliberal dos últimos trinta anos caminhou para privatizar o controle da tributação do lucro, tendo como uma das principais conquistas evitar que a parcela pública se ampliasse, por meio da criação de novos sistemas de governança alinhados aos interesses estatais e empresariais.

A democratização do direito à cidade, e a construção de um amplo movimento social para fazer valer a sua vontade são imperativos para que os despossuídos possam instituir novas formas de urbanização. Nesses termos, políticas públicas devem ser criadas com a participação constante de membros da sociedade civil. É através dessa participação que se promoverá a formação de uma consciência ecológica, vislumbrando-se o bem-estar da coletividade. O direito à cidade existe em termos legais, mas requer a formação de uma consciência crítica para que a qualidade de vida possa ser atingida de forma equitativa nas grandes cidades.

Por fim, cabe frisar que o direito à cidade se sobrepõe ao simples fato de se ter liberdade individual ou acesso aos recursos urbanos. Trata-se de direito de dimensão coletiva cujo exercício requer poder coletivo de moldar processos de urbanização. Àquele direito deve implicar, em última análise, a possibilidade de concretização dos chamados direitos humanos.

\section{REFERÊNCIAS BIBLIOGRÁFICAS}

ACSELRAD, Henri; MELLO, Cecília Campello do Amaral; BEZERRA, Gustavo das Neves. O que é justiça ambiental. Rio de Janeiro: Garamond, 2009.

ATLAS SOCIOECONÔMICO RIO GRANDE DO SUL. Taxa de Urbanização: Cerca de 85\% da população do RS vive em áreas urbanas. 2016. Disponível em: <https://atlassocioeconomico.rs.gov.br/grau-deurbanizacao>. Acesso em: 22 maio 2020.

BENEVOLO, Leonardo. História da cidade. Tradução de Silvia Mazza. São Paulo/SP: Perspectiva, 2017.

BODNAR, Zenildo; PRIESS, Alexandre dos Santos; BIANCHI, Patrícia Nunes Lima. A sustentabilidade por meio do planejamento urbano. Revista Brasileira de Direito, Passo Fundo, vol. 15, n. 3, p. 38-57, Setembro-Dezembro, 2019. Disponível em:

<https://seer.imed.edu.br/index.php/revistadedireito/article/view/3646>. Acesso em: 20 maio 2020.

BRASIL. Lei no 10.257, de 10 de julho de 2001. Regulamenta os arts. 182 e 183 da Constituição Federal, estabelece diretrizes gerais da política urbana e dá outras providências. Disponível em:

<http://www.planalto.gov.br/ccivil_03/leis/leis_2001/l10257.htm>. Acesso em: 21 maio 2020.

CAMERA, Sinara; MACIEL, Renata. A efetivação das funções sociais da cidade por intermédio da cidadania para a gestão democrática nas cidades. Revista de Direito da Cidade, vol. 11, no 3. pp.376- 
412. Disponível em: <https://www.e-publicacoes.uerj.br/index.php/rdc/article/view/38490/32515>. Acesso em: 20 maio 2020.

CANEPA, Carla. Cidades sustentáveis: o município como lócus da sustentabilidade. São Paulo/SP: RCS, 2007.

CARLOS, Ana Fani Alessandri. Henri Lefebvre: o espaço, a cidade e o "direto à cidade". Revista Direito \& Práxis. v. 11 n.1. Rio de Janeiro Jan./Mar. 2020. Disponível em: <https://www.scielo.br/scielo.php?pid=S2179-89662020000100349\&script=sci_arttext>. Acesso em: 24 maio 2020.

; SOUZA, Marcelo Lopes de; SPOSITO, Maria Encarnação Beltrão. (Orgs). A produção do espaço urbano: agentes e processos, escalas e desafios. São Paulo/SP: Contexto, 2017.

CARVALHO, Claudio; RODRIGUES, Raoni. O direito à cidade. Rio de Janeiro: Lumen Juris, 2016.

CORRÊA, Roberto Lobato. Segregação residencial: classes sociais e espaço urbano, p.39-59. In: VASCONCELOS, Pedro de Almeida; CORRÊA, Roberto Lobato; PINTAUDI, Silvana Maria. (Orgs.). A cidade contemporânea: segregação espacial. São Paulo/SP: Contexto, 2016.

CORREIA, Carlos Jorge Da Silva. Infográficos e a mobilização de jovens acerca de questões socioambientais: reflexões desde uma comunidade de aprendizagem na rede social facebook. 2017. 173 f. Dissertação (Mestrado em Ensino de Ciências e Matemática) - Centro de Educação, Programa de Pós Graduação em Ensino de Ciências e Matemática, Universidade Federal de Alagoas, Maceió, 2017. Disponível em: <http://www.repositorio.ufal.br/handle/riufal/2005>. Acesso em: 22 maio 2020.

DE MASI, Domenico. Criatividade e grupos criativos - vol.1: descoberta e invenção. Rio de Janeiro: Sextante, p. 1, 2005. In: CARVALHO, Claudio; RODRIGUES, Raoni. O direito à cidade. Rio de Janeiro: Lumen Juris, 2016.

DIAS, Daniella Maria dos Santos; ALBUQUERQUE, Maria Claudia Bentes. O direito à cidade nos interstícios do espaço público: parklets para que e para quem? Revista de Direito da Cidade. v. 11, no 3. pp. 347-375. Rio de Janeiro, 2019. Disponível em <https://www.e-

publicacoes.uerj.br/index.php/rdc/article/view/38408>. Acessoem: 18 maio 2020.

DIAS-PARRA, Iban; JOVER, Jaime. Overtourism, place alienation and the right to the city: insights from the historic centre of Seville, Spain. JournalofSustainable Tourism. Disponível em:

<https://www.tandfonline.com/doi/full/10.1080/09669582.2020.1717504?scroll=top\&needAccess=true >. Acesso em: 20 maio 2020.

EMERY, Emerson Baldotto. Desenvolvimento sustentável: Princípio da Eficiência em procedimentos licitatórios. Belo Horizonte: Fórum, 2016.

FREITAS, Juarez. Sustentabilidade: direito ao futuro. 2. ed. Belo Horizonte: Fórum, 2012.

GOLDMAN, Simão. A civilização do consumo em massa: entre a flor e o parafuso. Porto Alegre: Artes \& Letras, 1970

GONÇALVES JUNIOR, Luiz Claudio. As cidades sustentáveis e sua tutela jurídica à luz do Estatuto da Cidade, p.70-79. In: PACHECO, José Carlos et alli. Família, Direito Privado e Segurança Pública. Volta Redonda/RJ: FOA/UniFOA, 2017, 154p. Disponível em: <www.unifoa.edu.br/editorafoa>. Acesso em: 21 maio 2020. 
GOUCHER, Candice; WALTON, Linda. História Mundial: jornadas do passado ao presente. Tradução de Lia Gabriele Regius Reis. Porto Alegre: Penso, 2011.

HARVEY, David. O Direito à Cidade. Revista Piauí. Rio de Janeiro: Editora Alvinegra, 2013. Disponível em: <https://piaui.folha.uol.com.br/materia/o-direito-a-cidade/>. Acesso em: 18 maio 2020.

HIDAYATI, Isti; YAMU, Claudia; TAN, Wendy. The Emergence of Mobility Inequality in Greater Jakarta, Indonesia: A Socio-Spatial Analysis of Path Dependencies in Transport-Land Use Policies. Sustainability. v. 11 (18), pages 1-18, September, 2019. Disponível em:

<https://ideas.repec.org/a/gam/jsusta/v11y2019i18p5115-d268451.html>. Acesso em: 20 maio 2020.

IBGE. Instituto Brasileiro de Geografia e Estatística. Censo Demográfico 2010. Disponível em: <http://censo2010.ibge.gov.br>. Acesso em: 22 maio 2020.

KLUG, Letícia; AMANAJÁS, Roberta. Direito à cidade, cidades para todos e estrutura sociocultural urbana. In: A nova agenda urbana e o Brasil: insumos para sua construção e desafios a sua implementação. Orgs. COSTA, Marco Aurélio et al (Orgs.). Brasília: IPEA, 2018. Disponível em: <http://repositorio.ipea.gov.br/bitstream/11058/8622/1/Direito\%20\%c3\%a0\%20cidade.pdf >. Acesso em: 18 maio 2020.

LEFEBVRE, Henri. O direito à cidade. Tradução de Rubens Eduardo Frias. São Paulo/SP: Centauro, 2001.

MACHADO, Paulo Affonso Leme. Direito ambiental brasileiro. 24. ed. São Paulo: Malheiros, 2016.

MORIN, Edgar. Ciência com consciência. Rio de Janeiro: Bertrand Brasil, 2005.

; KERN, Anne Brigitte. Terra pátria. Porto Alegre: Sulina, 2011.

ONU. Brasil. Habitat III: países adotam nova agenda para urbanização sustentável. 2016. Disponível em: <https://nacoesunidas.org/habitat-iii-paises-adotam-nova-agenda-para-urbanizacao-sustentavel/>. Acesso em: 18 maio 2020.

RECH, Adir Ubaldo; RECH, Adivandro. Cidade sustentável, direito urbanístico e ambiental: instrumentos de planejamento. Caxias do Sul/RS: Educs, 2016.

ROLNIK, Raquel. O que é cidade. 3aed. Tatuapé/SP: Brasiliense (Coleção Primeiros Passos), 2012.

SACCONI, Luiz Antonio. Grande Dicionário Sacconi da Língua Portuguesa: comentado, crítico e enciclopédico. São Paulo: Nova Geração, 2010.

VASCONCELOS, Pedro de Almeida. Contribuição para o debate sobre processos e formas socioespaciais nas cidades, p.17-37. In: VASCONCELOS, Pedro de Almeida; CORRÊA, Roberto Lobato; PINTAUDI, Silvana Maria. (Orgs.). A cidade contemporânea: segregação espacial. São Paulo/SP: Contexto, 2016.

VEIGA, José Eli da. Desenvolvimento sustentável: o desafio do século XXI. Rio de Janeiro: Garamond, 2010.

Trabalho enviado em 29 de maio de 2020

Aceito em 13 de maio de 2021 